\title{
Genetic polymorphisms of exon I of MBL2 contribute to tuberculosis risk especially in Asian populations: an updated meta-analysis of 26 studies
}

This article was published in the following Dove Press journal:

Infection and Drug Resistance

\section{Yu-jiao $\mathrm{Wu}^{\mathrm{l}, *}$ \\ Xin Yang ${ }^{2, *}$ \\ Ting-di Chen ${ }^{3}$ \\ Zhi-xin Zhang ${ }^{4}$ \\ Yi-zhong You ${ }^{5}$ \\ Zheng-da Fan' \\ 'Department of Pharmacy, The Third People's Hospital, Changzhou, \\ China; ${ }^{2}$ Department of Oncology, \\ The Third Affiliated Hospital of \\ Soochow University, Changzhou, \\ China; ${ }^{3}$ Department of Science and \\ Education, The Third People's Hospital, \\ Changzhou, China; ${ }^{4}$ Department of \\ Pulmonary Tuberculosis, The Third \\ People's Hospital, Changzhou, China; \\ ${ }^{5}$ Department of Pharmacy, The Third \\ Affiliated Hospital of Soochow \\ University, Changzhou, China}

*These authors contributed equally to this work

Correspondence: Zheng-da Fan

Department of Pharmacy, The Third People's Hospital, No. 300 Lanlin Road,

Tianning District, Changzhou 213003,

China

$\mathrm{Tel} / \mathrm{Fax}+8651982009706$

Email ctzs567@I63.com

Xin Yang

Department of Oncology, The Third Affiliated Hospital of Soochow University, No. 185 Juqian Road, Tianning District, Changzhou 213003, China

Tel +865196887 I I 22

Email yangxindoctor@I63.com
Background: Evidence suggests that genetic variations of exon 1 of mannose-binding lectin 2 (MBL2) may contribute to tuberculosis (TB) risk. Many studies have investigated the association between MBL2 exon 1 polymorphisms (rs1800450, rs1800451, and rs5030737) and TB risk, but yielded inconclusive results.

Method: We conducted this meta-analysis of 26 eligible case-control studies that included 7952 cases and 9328 controls to identify the strength of association. Odds ratio (OR) and 95\% CI were used to evaluate the strength of association. Statistical analyses were performed by using STATA 12.1 .

Results: We found a statistically significant correlation between MBL2 exon 1 polymorphisms and increased TB risk among three models: allele model (O vs A: OR $=1.18,95 \%$ CI: 1.01 $1.38, P_{\text {heterogeneity }}<0.0001, P=85.8 \%$ ), homozygote comparison (OO vs AA: $\mathrm{OR}=1.49,95 \% \mathrm{CI}$ : $1.02-2.18, P_{\text {heterogeneity }}<0.0001, I^{2}=79.1 \%$ ), dominant model (AO/OO vs AA: OR $=1.20,95 \%$ CI: $1.01-1.43, P_{\text {heterogeneity }}<0.0001, P^{2}=83.5 \%$ ), especially in studies based on Asian populations among five models: allele model (O vs A: OR $=1.29,95 \% \mathrm{CI}: 1.11-1.51, P_{\text {heterogeneity }}<0.0001$, $I^{2}=66.0 \%$ ), homozygote comparison (OO vs AA: OR $=1.67,95 \% \mathrm{CI}: 1.09-2.55, P_{\text {heterogene- }}$ ity $=0.008, I^{2}=54.2 \%$ ), heterozygote comparison (AO vs AA: OR $=1.26,95 \% \mathrm{CI}: 1.05-1.50$, $\left.P_{\text {heterogeneity }}=0.001, I^{2}=62.9 \%\right)$, dominant model (AO/OO vs. AA: OR $=1.31,95 \% \mathrm{CI}: 1.10-1.56$, $\left.P_{\text {heterogeneity }}=0.001, I^{2}=64.2 \%\right)$, and recessive $\operatorname{model}(\mathrm{OO}$ vs AO/AA: $\mathrm{OR}=1.50,95 \% \mathrm{CI}: 1.01-2.22$, $\left.P_{\text {heterogeneity }}=0.023, I^{2}=48.0 \%\right)$. Meta-regression results revealed that source of controls $(p=0.009)$, but not ethnicity ( $p=0.687)$, genotyping $\operatorname{method}(p=0.231)$, and sample size $(p=0.451)$ contributed to the source of heterogeneity.

Conclusion: This meta-analysis suggests that MBL2 exon 1 polymorphisms may contribute to TB risk, especially in Asian populations.

Keywords: MBL2, rs1800450, rs1800451, rs5030737, tuberculosis, polymorphisms

\section{Introduction}

Mycobacterium tuberculosis is the causative agent of tuberculosis (TB) in humans and presumably infects a third of the world's population. ${ }^{1}$ According to the latest information of TB epidemic provided by the World Health Organization Global Tuberculosis Report 2017 , TB causes ill-health in 10 million people each year and is one of the top 10 causes of death worldwide. For the past 5 years, it has been the leading cause of death from a single infectious agent, ranking above HIV/AID. The innate immune response induces activation of the $\mathrm{T}$ helper 1-type immune system and plays an important role 
in host defense against the pathogenesis of TB. ${ }^{2}$ Unraveling genetic factors contributing to TB risk may lead to improved treatment and prevention of this disease. ${ }^{3,4}$

Mannose-binding lectin (MBL) is a calcium-dependent plasma collagenous lectin which plays an important role in innate immune defense against infectious agents. ${ }^{5} \mathrm{MBL}$ is synthesized in liver and circulates as oligomers complexed with MBL-associated serine proteases (MASPs) ${ }^{6}$ and the lectin pathway of the complement system, generating non-specific immune responses. ${ }^{7,8}$ MASPs are activated to initiate the lectin pathway of complement activation, which results in opsonization and phagocytosis or lysis of microorganisms. Besides its direct action as an opsonin and its key role in the lectin pathway, MBL may modulate inflammatory responses and immune activation. ${ }^{6}$

MBL production is encoded by the MBL2 gene that lies in chromosome 10, and polymorphisms of the structural regions of the gene or its promoter have been associated with relative or absolute serum MBL deficiencies. The presence of three mutations in exon 1 of the $M B L 2$ gene which are known for their functional effect at codons 52(rs5030737), 54(rs1800450), and 57(rs1800451). The three variants can impede the assembly of MBL subunits into the basic trimer structure and make the subunits more vulnerable to degradation, thereby reducing the amount of functional MBL subunits in heterozygous individuals. ${ }^{9}$ The variant mutant alleles are allele B of codon 54, allele C of codon 57, and allele D of codon 52 in exon 1 . The normal wild-type allele is commonly designated as $\mathrm{A}$, and the three variant alleles are designated as $\mathrm{O} .{ }^{9-11}$ A number of genetic studies have been performed to consider the impact of MBL2 polymorphisms on the development of TB disease, leading to conflicting results. A previous meta-analysis suggested that MBL2 polymorphisms were not significantly associated with susceptibility to pulmonary TB infection, ${ }^{12}$ while another meta-analysis demonstrated that MBL2 exon 1 polymorphisms (rs1800451 and rs1800451) played a protective role against the development of TB disease. Recently several new case-control studies have been published, some of which reported controversial results compared with previous publications.

In this study, we comprehensively collected and pooled all eligible articles using meta-analysis with the aim to better clarify the association between currently reported MBL2 exon 1 polymorphisms and TB susceptibility.

\section{Materials and methods Search strategy}

This meta-analysis was conducted and reported in accordance with the PRISMA guidelines. We performed a systematic search of relevant literature using the databases PubMed, EMBASE, Chinese National Knowledge Infrastructure, and Chinese Biomedical database up to February 2, 2018 without time period and sample size limitations. The combination of search items included MeSH items and keywords of "mannose-binding lectin 2" or "MBL2"; "rs1800450" or "rs1800451" or "rs5030737" or "polymorphism(s), single nucleotide" or "variant" or "variation" or "allele" or "SNP"; "tuberculosis" (Supplementary material). Moreover, reference lists of related review articles, original studies, and conference abstracts were manually screened to identify additional articles that were not identified in the initial literature search described above.

\section{Inclusion and exclusion criteria}

Studies were selected according to the following inclusion criteria: 1) case-control studies; 2) investigation on the association of MBL2 exon 1 polymorphisms (rs1800450, rs1800451, and rs5030737) with TB risk; 3) genotype distribution information in cases and controls. The major reasons for exclusion of studies were 1) repeated literature; 2) case-only studies and review articles; 3) studies without detailed genotype frequencies; 4) genotype frequencies found in the control group deviate from Hardy-Weinberg equilibrium (HWE).

\section{Data extraction}

Data of eligible studies were independently extracted by two authors ( $\mathrm{Wu}$ and Yang) according to the above-mentioned selection criteria. The two authors reached a consensus on each item. The following data were collected: name of the first author, publication year, country where the study was conducted, ethnicity, source of controls, genotyping method, TB types, genotype frequency in cases and controls, and HIV status. Different ethnicities were categorized as Asian, Caucasian, and African. TB types were classified as pulmonary tuberculosis (PTB) and extrapulmonary tuberculosis (EPTB). All eligible studies were classified as hospital-based (HB), population-based (PB), and household/neighboring/ working contacts-based (H/N/WB) according to the source of controls. The HWE in control population was judged by chi-square test. $P$-value $<0.05$ was considered as a state of significant disequilibrium.

\section{Statistical analysis}

Crude odds ratio (OR) with $95 \%$ confidence intervals (CIs) were calculated to investigate the strength of the association between MBL2 exon 1 polymorphisms (rs1800450, 
rs 1800451, and rs5030737) and TB risk. The 95\% CIs were used for statistical significance test and a 95\% CI without 1.00 suggested significant difference. Pooled ORs were obtained from combination of single studies by five models: allele model (O vs A), homozygote comparison (OO vs $\mathrm{AA}$ ), heterozygote comparison (AO vs AA), dominant model (AO/OO vs AA), and recessive model (OO vs $\mathrm{AO} /$ AA). Chi-square-based Q-test was applied to test the heterogeneity assumption, and the $P$-value of $<0.1$ was considered to detect notable heterogeneity. ${ }^{13}$ When Q-test showed the existence of notable heterogeneity, we used the randomeffects model (DerSimonian and Laird method); ${ }^{14}$ otherwise, the fixed-effects model (Mantel and Haenszel method) was applied for the pooling of the data. ${ }^{15} I^{2}$ statistics was used to measure inter-study variability, and greater values indicated higher degree of heterogeneity. ${ }^{13}$ Sensitivity analysis was conducted by removing one data set at a time to reflect the influence of the individual data set to the pooled ORs and assess the stability of the results. Stratification and logistic meta-regression analyses were performed to explore the source of heterogeneity by ethnicity, source of controls, genotyping method, and sample size (studies with $>800$ participants were defined as "large," and studies with $<800$ participants were defined as "small"). Publication bias was assessed using Begg's funnel plots ${ }^{16}$ and Egger's regression method, ${ }^{17}$ statistical significance was defined as $P$-value $<0.05$. All $P$-values are two-sided. Statistical analysis was undertaken using STATA software (version 12.1; Stata Corp, College Station, TX, USA).

\section{Results \\ Study selection and characteristics of studies}

Previous studies have provided conflicting results about MBL2 exon 1 polymorphisms and TB risk; hence, it is necessary to clarify this association by a comprehensive meta-analysis. Figure 1 illustrates the study selection process. A total of 26 case-control studies, ${ }^{18-43}$ including 7952 cases and 9328 controls, were identified according to inclusion and exclusion criteria. The time span of eligible studies was from January 1, 1998 to May 4, 2017. Among the 26 eligible studies, 14 were studies of Asians, nine studies were of Caucasians, and three studies were of Africans. The detailed characteristics of the eligible studies included in this meta-analysis are shown in Table 1.

\section{Meta-analysis results}

The association strengths between MBL2 exon 1 polymorphisms with TB risk are shown in Table 2. Overall, a

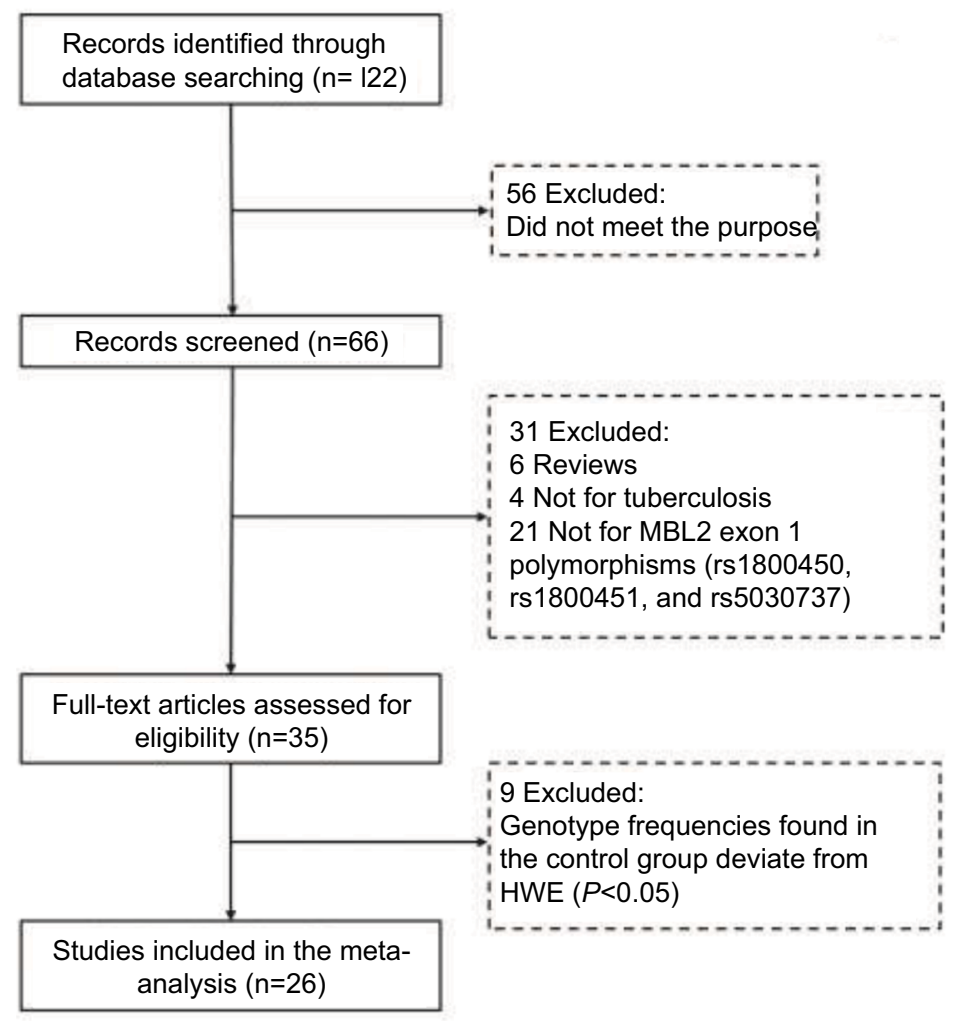

Figure I PRISMA flowchart. The flow diagram of included and excluded studies. Abbreviations: MBL2, mannose-binding lectin 2; HWE, Hardy-Weinberg equilibrium. 
Table I Characteristics of eligible studies

\begin{tabular}{|c|c|c|c|c|c|c|c|c|c|c|c|c|c|}
\hline \multirow[t]{2}{*}{ Study } & \multirow[t]{2}{*}{ Year } & \multirow[t]{2}{*}{ Country } & \multirow[t]{2}{*}{ Ethnicity } & \multirow[t]{2}{*}{ Control } & \multirow{2}{*}{$\begin{array}{l}\text { Genotyping } \\
\text { method }\end{array}$} & \multirow[t]{2}{*}{ Type } & \multicolumn{3}{|c|}{ Cases } & \multicolumn{3}{|c|}{ Controls } & \multirow[t]{2}{*}{ HIV } \\
\hline & & & & & & & $\overline{\mathbf{A A}}$ & AO & OO & $\overline{\mathbf{A A}}$ & AO & OO & \\
\hline Bellamy et $\mathrm{al}^{40}$ & 1998 & Gambia & African & $\mathrm{HB}$ & PCR-SSP & PTB & 198 & 166 & 33 & 183 & 197 & 42 & - \\
\hline Selvaraj et $\mathrm{a}^{28}$ & 1999 & India & Asian & $\mathrm{H} / \mathrm{N} / \mathrm{WB}$ & PCR-SSP & PTB & 107 & 73 & 22 & 68 & 39 & 2 & ND \\
\hline Ozbas-Gerceker et a $\left.\right|^{30}$ & 2003 & Turkey & Caucasian & $\mathrm{PB}$ & PCR-SSP & PTB & 40 & 9 & 0 & 76 & 20 & 4 & - \\
\hline Soborg et $\mathrm{al}^{26}$ & 2003 & Denmark & Mixed & PB & PCR-SSP & $\mathrm{TB}$ & 142 & 60 & 16 & 157 & 86 & 7 & - \\
\hline Fitness et $\mathrm{al}^{36}$ & 2004 & Malawi & African & PB & PCR-RFLP & PTB & 205 & 105 & 12 & 362 & 160 & 24 & - \\
\hline Garcia-Laorden et a $\left.\right|^{34}$ & 2006 & Spain & Caucasian & $\mathrm{HB}$ & PCR-RFLP & $\mathrm{TB}$ & 144 & 79 & 10 & 183 & 134 & 27 & + \\
\hline Selvaraj et $\mathrm{al}^{29}$ & 2006 & India & Asian & $\mathrm{HB}$ & PCR-SSP & PTB & 24 & 19 & 5 & 37 & 18 & 3 & - \\
\hline Liu et $\mathrm{al}^{32}$ & 2007 & China & Asian & PB & PCR-SSP & РTB & 103 & 34 & 4 & 166 & 42 & 4 & - \\
\hline Alagarasu et $\mathrm{al}^{43}$ & 2007 & India & Asian & PB & PCR-SSP & РTB, EPTB & 145 & 87 & 25 & 86 & 53 & 7 & $+1-$ \\
\hline Cosar et $\mathrm{al}^{38}$ & 2008 & Turkey & Caucasian & $\mathrm{HB}$ & PCR-RFLP & PTB, EPTB & 40 & 4 & 0 & 71 & 27 & I & - \\
\hline $\mathrm{Li}^{19}$ & 2009 & China & Asian & PB & PCR-SSP & PTB & 79 & 56 & 6 & 106 & 38 & 8 & - \\
\hline Capparelli et al ${ }^{39}$ & 2009 & Italy & Caucasian & H/N/WB & PCR-RFLP & PTB & 55 & 158 & 61 & 166 & 112 & 10 & - \\
\hline Li et $\mathrm{a}^{20}$ & 2011 & China & Asian & $\mathrm{PB}$ & Pyrosequencing & PTB & $17 \mid$ & 57 & 3 & 186 & 37 & 3 & - \\
\hline Fang and $Y_{i n}{ }^{2 !}$ & 2011 & China & Asian & $\mathrm{HB}$ & PCR-SSP & PTB & 75 & 25 & 0 & 74 & 25 & I & - \\
\hline Thye et $\mathrm{al}^{25}$ & 2011 & Ghana & African & $\mathrm{H} / \mathrm{N} / \mathrm{WB}$ & PCR-SSP & РTB & 887 & 814 & 193 & 1002 & 977 & 257 & - \\
\hline Singla et $\mathrm{al}^{27}$ & 2012 & India & Asian & PB & PCR-RFLP & PTB, EPTB & 218 & 126 & 13 & 207 & 155 & 30 & - \\
\hline Zhou and Zhang ${ }^{22}$ & 2012 & China & Asian & PB & PCR-SSP & PTB & 106 & 106 & 14 & 146 & 80 & 5 & - \\
\hline Ocejo-Vinyals et $\mathrm{al}^{31}$ & 2012 & Spain & Caucasian & PB & PCR-SSP & PTB & 74 & 31 & 2 & 272 & 146 & 23 & - \\
\hline $\mathrm{Da}$ et $\mathrm{al}^{37}$ & 2013 & Brazil & Caucasian & PB & Sequencing & PTB, EPTB & 92 & 55 & 8 & 108 & 34 & 6 & - \\
\hline Araujo et $\mathrm{al}^{41}$ & 2013 & Brazil & Caucasian & $\mathrm{HB}$ & PCR-SSP & PTB, EPTB & 102 & 62 & 3 & 101 & 56 & 2 & - \\
\hline Garcia-Gasalla et a ${ }^{35}$ & 2014 & Spain & Caucasian & $\mathrm{H} / \mathrm{N} / \mathrm{WB}$ & PCR-SSP & PTB, EPTB & 48 & 24 & 4 & 72 & 33 & I & - \\
\hline Zhao et al $\left.\right|^{18}$ & 2014 & China & Asian & $\mathrm{PB}$ & PCR-RFLP & PTB & 520 & 279 & 101 & 514 & 303 & 53 & - \\
\hline Wu et $\mathrm{al}^{24}$ & 2015 & China & Asian & $\mathrm{HB}$ & PCR-SSP & PTB & 112 & 37 & 2 & 348 & 97 & 8 & - \\
\hline Liu et $\mathrm{al}^{23}$ & 2016 & China & Asian & $\mathrm{HB}$ & PCR-SSP & PTB & 100 & 36 & 6 & 96 & 22 & 2 & - \\
\hline Liu et $\mathrm{al}^{33}$ & 2016 & China & Asian & PB & PCR-RFLP & PTB & 645 & 345 & 30 & 748 & 258 & 14 & - \\
\hline Amiri et $\mathrm{al}^{42}$ & 2017 & Iran & Asian & PB & PCR-SSP & PTB & 69 & 29 & 2 & 72 & 27 & 1 & - \\
\hline
\end{tabular}

Note: Mixed=Caucasian/Asian/Africans/Inuits.

Abbreviations: PB, population-based; HB, hospital-based; H/N/WB, household/neighboring/working contacts; PCR-SSP, polymerase chain reaction-sequence-specific primers; PCR-RFLP, polymerase chain reaction-restrictive fragment length polymorphism; TB, tuberculosis; PTB, pulmonary tuberculosis; EPTB, extrapulmonary tuberculosis; HIV, human immunodeficiency virus; ND, not mentioned.

statistically significant increased risk of TB susceptibility was observed in allele model $(\mathrm{O}$ vs $\mathrm{A}: \mathrm{OR}=1.18,95 \%$ $\mathrm{CI}=1.01-1.38, P_{\text {heterogeneity }}<0.0001, I^{2}=85.8 \%$, Figure $2 \mathrm{~A}$ ), homozygote comparison (OO vs AA: $\mathrm{OR}=1.49,95 \% \mathrm{CI}$ : $1.02-2.18, P_{\text {heterogeneity }}<0.0001, I^{2}=79.1 \%$ ), and dominant model (AO/OO vs AA: OR $=1.20,95 \%$ CI: $1.01-1.43$, $P_{\text {heterogeneity }}<0.0001, I^{2}=83.5 \%$, Figure $2 \mathrm{~B}$ ). Furthermore, we performed subgroup analyses to explore the effect of ethnicity, TB types, source of control, genotyping method, and sample size.

In subgroup analyses (Table 2), when data were stratified according to ethnicity, a significant increased TB risk was found in allele model $(\mathrm{O}$ vs A: $\mathrm{OR}=1.29,95 \% \mathrm{CI}=1.11-1.51$, $P_{\text {heterogeneity }}<0.0001, I^{2}=66.0 \%$, Figure $2 \mathrm{~A}$ ), homozygote comparison (OO vs AA: OR $=1.67,95 \%$ CI: $1.09-2.55$, $P_{\text {heterogeneity }}=0.008, P^{2}=54.2 \%$ ), heterozygote comparison (AO vs AA: OR $=1.26,95 \%$ CI: $1.05-1.50, P_{\text {heterogeneity }}=0.001$, $\left.I^{2}=62.9 \%\right)$, dominant model $(\mathrm{AO} / \mathrm{OO}$ vs $\mathrm{AA}: \mathrm{OR}=1.31$, $95 \%$ CI: $1.10-1.56, P_{\text {heterogeneity }}=0.001, P^{2}=64.2 \%$, Figure $2 \mathrm{~B}$ ), and recessive model (OO vs $\mathrm{AO} / \mathrm{AA}$ : $\mathrm{OR}=1.50,95 \% \mathrm{CI}$ :
$1.01-2.22, P_{\text {heterogeneity }}=0.023, P^{2}=48.0 \%$ ) for Asians. However, no significant association except a decreased trend was found in each model for Africans.

Likewise, when stratified by TB types, we found a significantly increased risk only in PTB among four models: allele model ( $\mathrm{O}$ vs A: $\mathrm{OR}=1.23,95 \% \mathrm{CI}=1.04,1.44$, $P_{\text {heterogeneity }}<0.0001, I^{2}=85.7 \%$ ), homozygote comparison (OO vs AA: $\mathrm{OR}=1.58,95 \% \mathrm{CI}: 1.05-2.36, P_{\text {heterogeneity }}<0.0001$, $I^{2}=79.2 \%$ ), heterozygote model (AO vs AA: $\mathrm{OR}=1.23,95 \%$ CI: $1.04-1.45, P_{\text {heterogeneity }}<0.0001, I^{2}=77.8 \%$ ), and dominant model $(\mathrm{AO} / \mathrm{OO}$ vs AA: $\mathrm{OR}=1.26,95 \%$ CI: $1.05-1.51$, $\left.P_{\text {heterogeneity }}<0.0001, I^{2}=83.2 \%\right)$. As for source of controls, high susceptibility to TB was found in PB studies (O vs A: OR $=1.18,95 \%$ CI: $1.01-1.38, P_{\text {heterogeneity }}<0.0001, I^{2}=72.3 \%$ ). When stratified by genotyping method, the increased TB susceptibility was shown in polymerase chain reactionsequence specific primers (PCR-SSP) group among four models: allele model $(\mathrm{O}$ vs A: $\mathrm{OR}=1.27,95 \% \mathrm{CI}=1.03-1.58$, $P_{\text {heterogeneity }}<0.0001, I^{2}=84.2 \%$ ), homozygote comparison (OO vs AA: $\mathrm{OR}=1.96,95 \%$ CI: $1.07-3.57, P_{\text {heterogeneity }}<0.0001$, 


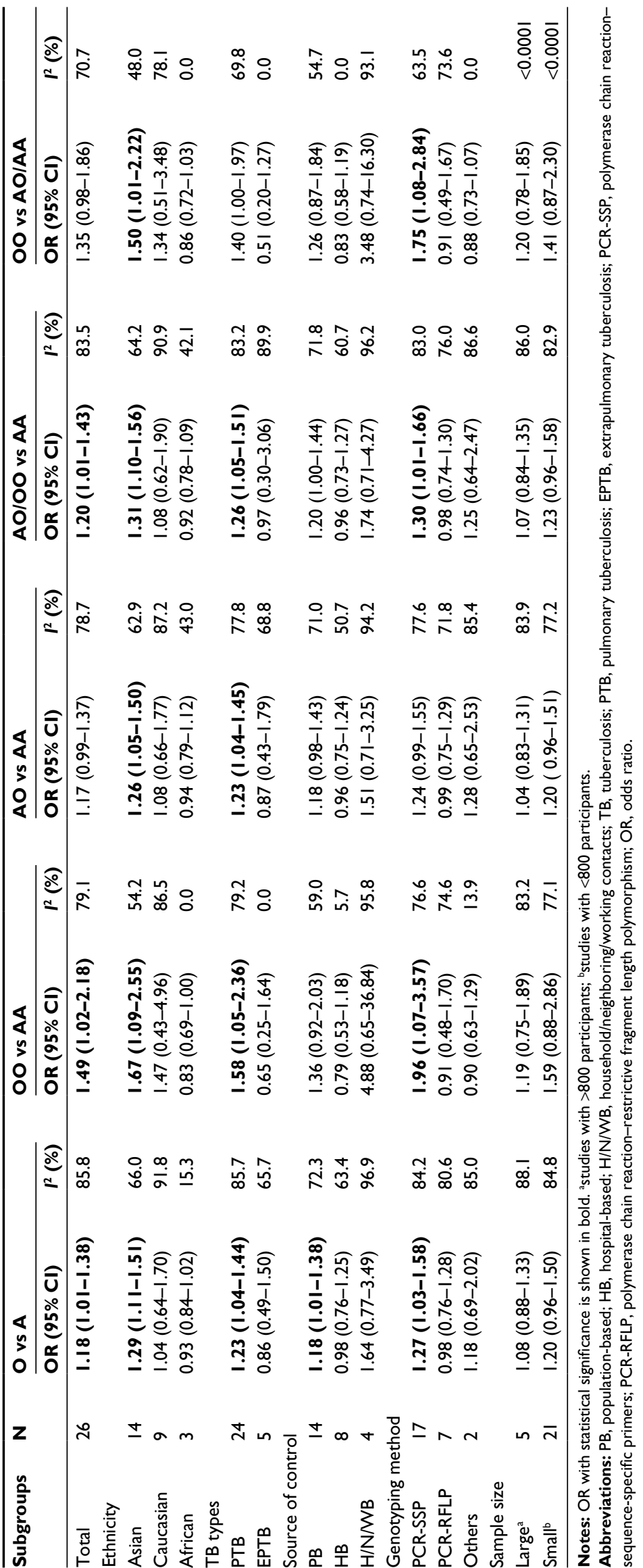


A

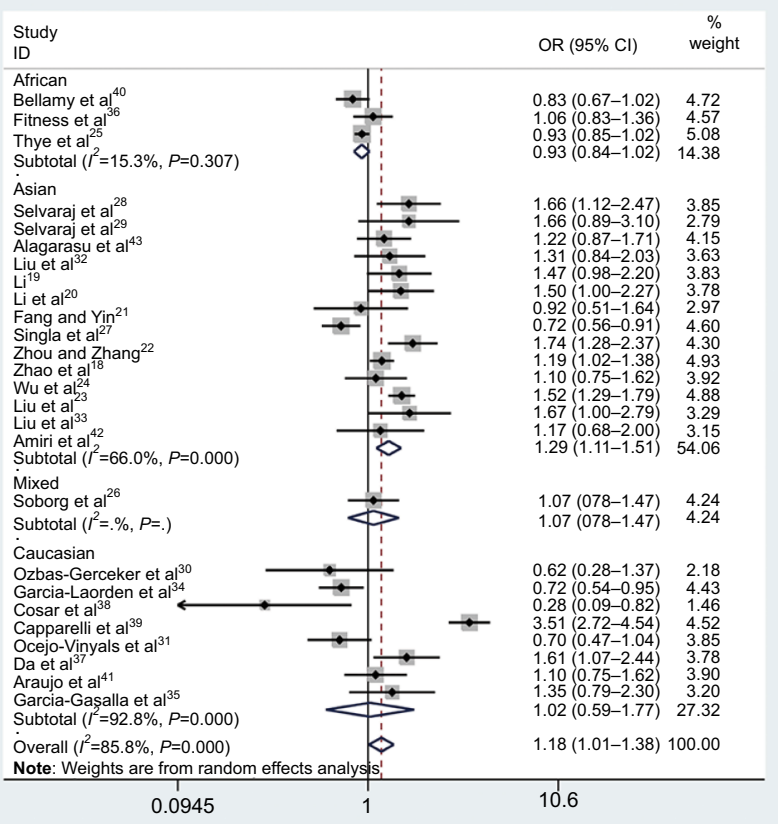

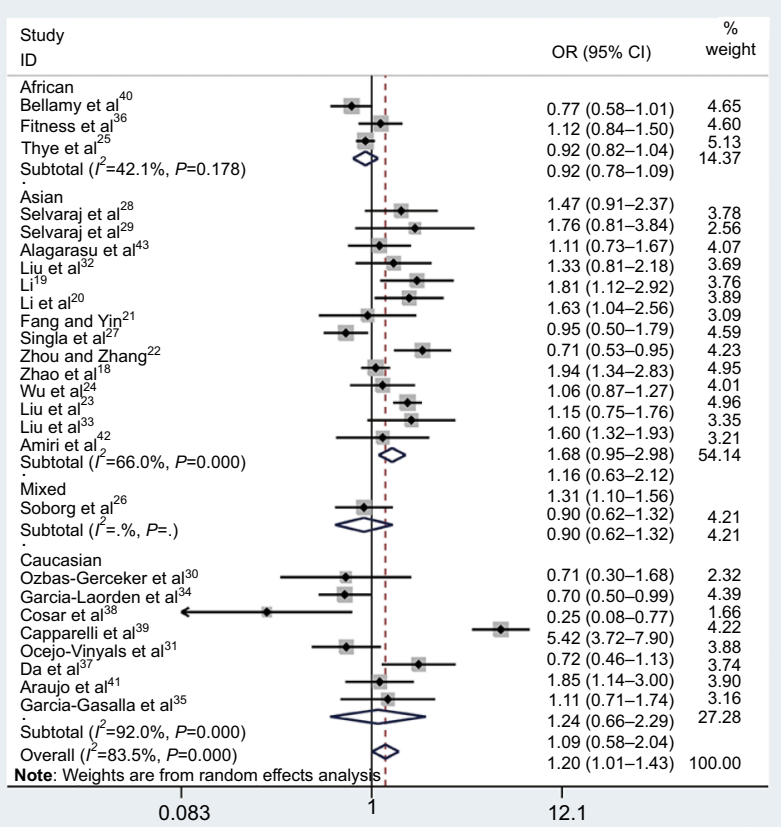

Figure 2 Meta-analysis for the association between the MBL2 exon I polymorphisms and tuberculosis risk. Forest plot of $(\mathbf{A})$ allele model $(\mathrm{O}$ vs $\mathrm{A})$ and $(\mathbf{B})$ dominant model (AO/OO vs AA).

Note: The arrow indicates that the lower limit values of the $95 \% \mathrm{Cl}$ are too low to be shown in the figure.

Abbreviations: MBL2, mannose-binding lectin 2; OR, odds ratio.

$\left.I^{2}=76.6 \%\right)$, dominant model $(\mathrm{AO} / \mathrm{OO}$ vs $\mathrm{AA}: \mathrm{OR}=1.30$, $95 \%$ CI: $\left.1.01-1.66, P_{\text {heterogeneity }}<0.0001, P=83.0 \%\right)$, and recessive model (OO vs AO/AA: OR $=1.75,95 \%$ CI: $1.08-2.84$, $\left.P_{\text {heterogeneity }}<0.0001, I^{2}=63.5 \%\right)$. Further analyses stratified by sample size showed no significant associations between MBL2 exon 1 polymorphisms and TB risk either in "large" or "small" studies. Note that three studies based on Africans are all "large" studies, which may be explained as a negative result in "large" studies.

\section{Heterogeneity and sensitivity analysis}

Heterogeneity between studies in each model is given in Table 2. The source of heterogeneity across studies was detected among covariables, including ethnicity, source of controls, sample size, and genotyping method. Meta-regression results revealed that the source of controls $(P=0.009)$, but not ethnicity $(P=0.687)$, genotyping method $(P=0.231)$, and sample size $(P=0.451)$ contributed to the source of heterogeneity. When significant heterogeneity existed, we adopted random-effects model; otherwise, we adopted fixedeffects models. To evaluate the effect of individual studies for the risk of overall TB, we performed leave-one-out sensitivity analysis and recomputed the pooled ORs. The estimated pooled ORs calculated after excluding a single study show some differences from the primary values of the overall risk of TB (Figure 3A), because the statistical significance is marginal. However, no single study affected the pooled ORs qualitatively in Asians (Figure 3B). It suggests that the results of this meta-analysis are stable and robust in Asians.

\section{Publication bias analysis}

Begg's funnel plot and Egger's test were conducted to evaluate the publication bias. The shape of the funnel plot both showed symmetry for overall and Asian risk of TB (Figure 4). Furthermore, the Egger's test also indicated that there was no evidence for publication bias in all populations $(P=0.373$ for allele model; $P=0.352$ for dominant model) and Asians ( $P=0.632$ for allele model; $P=0.566$ for dominant model).

\section{Discussion}

TB is an infectious disease caused by M. tuberculosis. Although about a third of the world's population are infected with $M$. tuberculosis, only $10 \%$ of them develop TB. In addition to factors of environmental, economic, and social status, genetic background of the host may play an important role. ${ }^{44}$ Genetic variations can influence their mechanism of action leading to variable immune response. Host genetic factors such as MBL2 gene polymorphisms can determine differences in the susceptibility or resistance to TB..$^{45}$ Recently, more studies have been conducted to identify whether the 
A

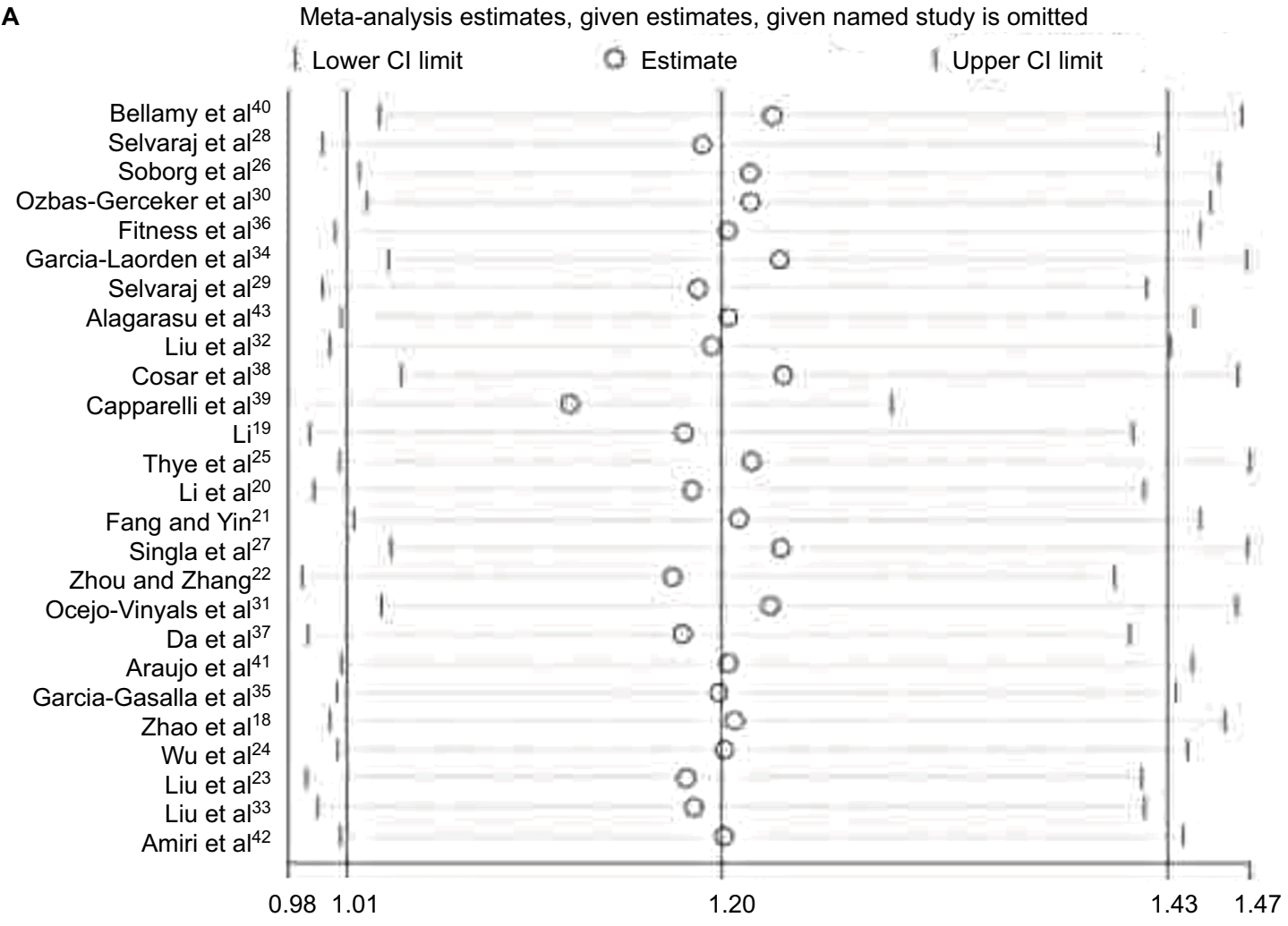

$\begin{array}{lll}0 & 0 \\ 0 & \\ 0 & 0 \\ 0 & 0 & 1 \\ 0 & 0 \\ 0 & 0 \\ 0 & 0 \\ 0 & 0 \\ 0 & 0 \\ 0 & \end{array}$

B

Meta-analysis estimates, given named study is omitted

I Lower Cl limit

Selvaraj et $\mathrm{al}^{28}$
Selvaraj et $\mathrm{al}^{29}$

Alagarasu et $\mathrm{al}^{43}$

Liu et $\mathrm{al}^{32}$
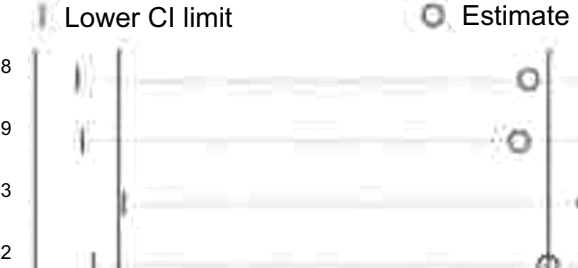

$\mathrm{Li}^{19}$
Li et $\mathrm{al}^{20}$
Fang and $\mathrm{Yin}^{21}$
Singla et $\mathrm{al}^{27}$

Zhou and Zhang ${ }^{22}$

Zhao et al $^{18}$

Wu et $\mathrm{al}^{24}$

Liu et $\mathrm{al}^{23}$

Liu et $\mathrm{al}^{33}$

Amiri et $\mathrm{al}^{42}$
O. Estimate

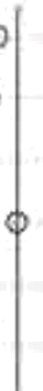

$\circ$

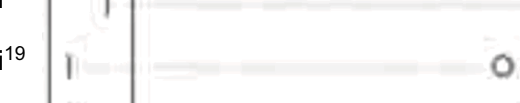

1

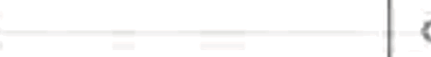

1. Upper Cl limit

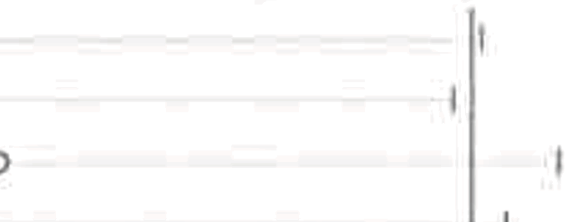



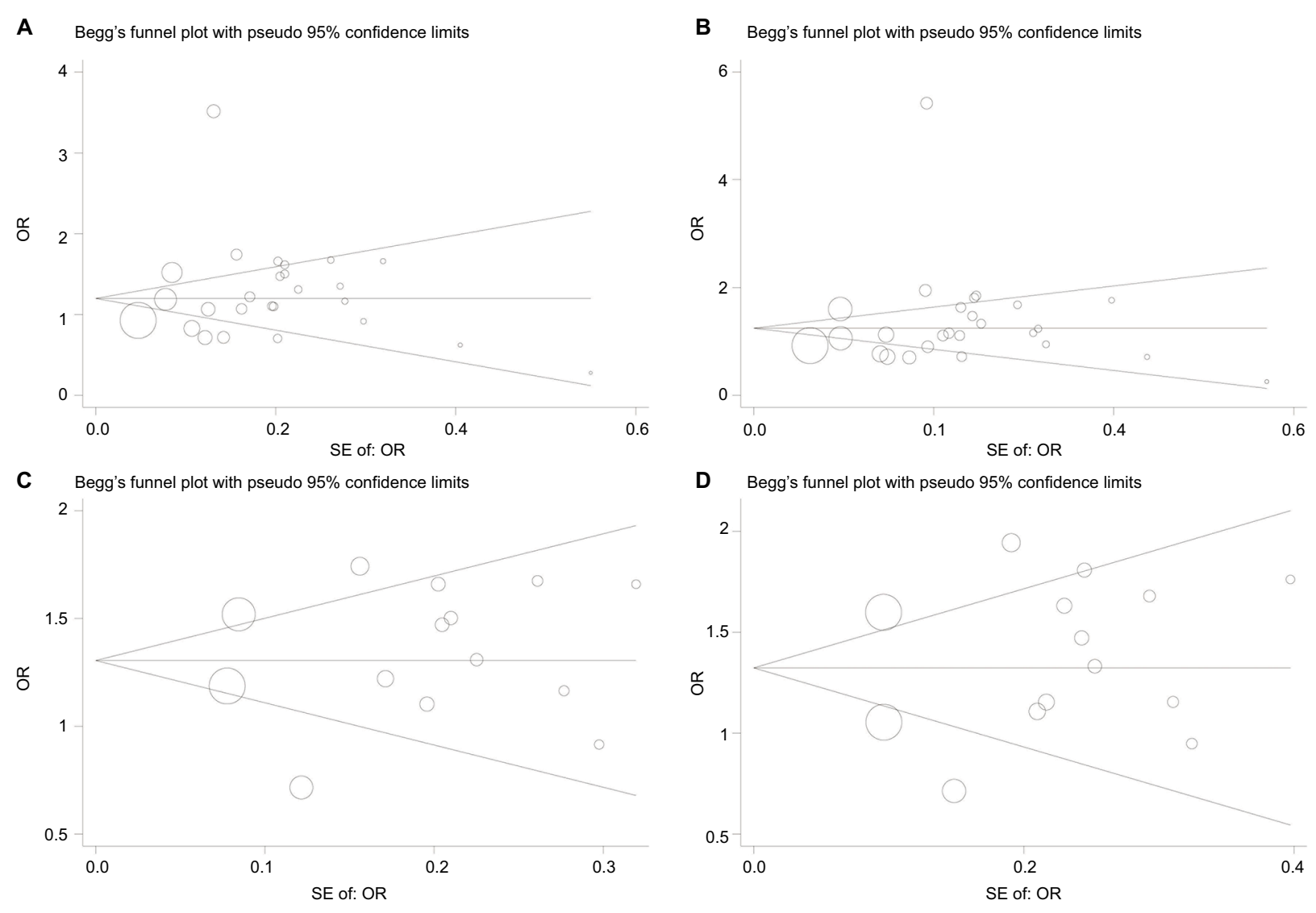

Figure 4 Funnel plot analysis to detect publication bias. Funnel plot analysis of $(\mathbf{A})$ allele model $(O$ vs $A)$ on all populations; (B) dominant model (AO/OO vs $A A)$ on all populations; (C) allele model (O vs A) on Asians; and (D) dominant model (AO/OO vs AA) on Asians.

Note: The circles represent the weight of individual study.

Abbreviations: SE, standard error; OR, odds ratio.

polymorphisms of exon 1 of MBL2 is the genetic determiner of TB. However, these studies yielded different or even controversial results. In this meta-analysis, a total of 26 case-control studies, including 7952 cases and 9328 controls, were identified and analyzed. Several similar system reviews had been performed on the association between MBL2 gene polymorphisms and TB risk, ${ }^{12,46}$ but it failed to confirm a significant result or in contrast with our study. This meta-analysis first reports that MBL2 exon 1 polymorphisms could predict the susceptibility of TB, especially in Asians.

HWE is essential for a sound case-control study. It is probable that studies without HWE in controls have selection bias or genotyping error, which may cause misleading results. Compared with previous studies, we dropped nine studies ${ }^{47-55}$ with $P_{\mathrm{HWE}}<0.05$ to enhance the article rigor and persuasiveness. Frequency distribution of genotypes and alleles of MBL2 exon 1 polymorphisms among different ethnic populations may lead to variable susceptibility to the infection. In this meta-analysis based on 26 eligible studies, we found a marginal significant increased risk in the allele model (O vs A, Figure 2A), homozygote comparison (OO vs $\mathrm{AA})$, and dominant model (AO/OO vs AA, Figure $2 \mathrm{~B})$ in all populations. Although the positive result was first reported, the statistical power was weak while the sensitivity analysis revealed the result was relatively unstable (Figure 3A). Moreover, the burden of TB is highest in Asia and Africa geographically. So we performed a subgroup analysis on ethnicity in this meta-analysis (Figure 2). It showed that the MBL2 exon 1 polymorphisms had a significantly increased risk of TB only in Asians among all five comparison models. However, no significant association between MBL2 exon 1 polymorphisms and TB risk was found in Caucasians, except a trend of decreased risk was found in Africans. We tried to discuss the further reasons as follows: First, the racial differences of MBL2 exon 1 mutation frequency may be a leading cause. The B allele is common in Caucasians, Chinese, and Eskimos with gene frequencies of $0.11-0.17$, while the $\mathrm{C}$ allele is almost exclusively present in Africans with a higher frequency (0.23-0.29)..$^{10,56-58}$ The D allele is present in both Caucasians and Africans with a lower frequency ( 0.05 in both). ${ }^{3}$ 
Second, TB types (PTB/EPTB) may influence the pooled result and high variability. For example, the result of Cosar et al study ${ }^{38}$ was quite different from other studies based on Caucasians. In this study, a significant reduction was observed in the frequency of the $\mathrm{AO}$ genotype and $\mathrm{O}$ allele in $\mathrm{TB}$ patients, especially in EPTB patients. Singla et al suggested that the mutant $\mathrm{O}$ allele might confer a protective role against TB, but failed in EPTB. ${ }^{27}$ Third, among the nine studies based on Caucasians, Cosar et $a{ }^{38}$ was the only study investigating MBL2 exon 1 polymorphisms in TB-affected children, thus we supposed that age should be also considered as a critical factor accounting for the differences. Fourth, TB susceptibility is usually influenced by codominant multiple genes, and the gene linkage disequilibrium is easy to be ignored.

During other subgroup analyses (Table 2), we found that different genotyping method might greatly affect the association between MBL2 exon 1 polymorphisms and TB risk. As shown in Table 2, there was a significantly increased TB risk in studies based on PCR-SSP, but no significant association was found in studies based on polymerase chain reaction-restrictive fragment length polymorphism (PCRRFLP). Screening for mutations prior to sequencing can reduce the time and costs of identifying mutations. When the DNA sequence is known, the technique of detecting mutations as PCR-SSP and PCR-RFLP are both convenient methods of screening for possible mutations. The differences on subgroup analyses by genotyping method may be due to different primer design and restriction enzyme cutting sites. In addition, the positive results were only found in PTB when stratified by TB types. Compared with PTB, EPTB is difficult to diagnose clinically. Risk factors involved in the development of EPTB are mainly age, female gender, concurrent HIV infection, and comorbidities such as chronic renal disease, diabetes mellitus, or immunosuppression. Less studies on EPTB and its specific pathogenesis may result in above-mentioned differences.

Note that the heterogeneity between studies is quite high in this meta-analysis. The high variability found in available literature may be related to a series of factors such as the ethnic origin of the study population, inadequate selection criteria of controls, small sample size, incomplete genotyping, and so on. In this meta-analysis, we found that only the source of controls might contribute to the high heterogeneity by meta-regression $(P=0.009)$. When studies were stratified by ethnicity and source of controls, low heterogeneity was found in Africans and HB studies. Hence, we considered that the racial differences and selection criteria of controls in each study might be responsible for the foremost source of heterogeneity. For example, Asians defined in most studies and this meta-analysis included Indians and Chinese (Han, Uighur, Hui, and Zhuang population) which contribute to obvious racial diversity. In addition, there are great variabilities in the living environment of controls in each study. The gene-environment interaction may influence the results so that it will cause the inevitable heterogeneity.

However, there were some limitations in this metaanalysis. First, we searched English and Chinese databases. Although no publication bias was showed in Begg's funnel plot and Egger's test, it was difficult to avoid the language selection bias completely. Second, the number of studies was relatively insufficient for some subgroup analyses such as by HIV status. It might mask or exaggerate possible true associations. Third, due to lack of detailed individual data, we failed to assess the influence of potential confounding factors more accurately.

\section{Conclusion}

In conclusion, we demonstrate that MBL2 exon 1 polymorphisms may contribute to TB risk, especially in Asian populations. Further investigations are needed to confirm the current findings.

\section{Acknowledgments}

This work was supported by grants from the Natural Science Youth Foundation of China (81501971 to Xin Yang), the Natural Science Youth Foundation of Jiangsu Province (BK20150252 to Xin Yang), the Human Resource Summit Grant of Jiangsu Province (WSW-142 to Xin Yang), and the Youth Medical Professionals Foundation of Jiangsu Province (QNRC2016279 to Xin Yang).

\section{Author contributions}

All authors contributed toward data analysis, drafting, and revising the paper and agree to be accountable for all aspects of the work.

\section{Disclosure}

The authors report no conflicts of interest in this work.

\section{References}

1. Ducati RG, Ruffino-Netto A, Basso LA, Santos DS. The resumption of consumption - a review on tuberculosis. Mem Inst Oswaldo Cruz. 2006;101(7):697-714.

2. Dorhoi A, Reece ST, Kaufmann SH. For better or for worse: the immune response against Mycobacterium tuberculosis balances pathology and protection. Immunol Rev. 2011;240(1):235-251.

3. Wu YJ, Yang X, Wang XX, et al. Association of vitamin D receptor BsmI gene polymorphism with risk of tuberculosis: a meta-analysis of 15 studies. PLoS One. 2013;8(6):e66944. 
4. Wang H, Pang C, Zeng N, Wan C, Shen Y, Wen F. Association between the IL-6 gene polymorphism and tuberculosis risk: a meta-analysis. Infect Drug Resist. 2017;10:445-454.

5. Heitzeneder S, Seidel M, Forster-Waldl E, Heitger A. Mannan-binding lectin deficiency - good news, bad news, doesn't matter? Clin Immunol. 2012;143(1):22-38.

6. Ip WK, Takahashi K, Ezekowitz RA, Stuart LM. Mannose-binding lectin and innate immunity. Immunol Rev. 2009;230(1):9-21.

7. Turner MW. Mannose-binding lectin: the pluripotent molecule of the innate immune system. Immunol Today. 1996;17(11):532-540.

8. Matsushita M, Endo Y, Fujita T. Cutting edge: complement-activating complex of ficolin and mannose-binding lectin-associated serine protease. J Immunol. 2000;164(5):2281-2284.

9. Madsen HO, Garred P, Thiel S, et al. Interplay between promoter and structural gene variants control basal serum level of mannan-binding protein. J Immunol. 1995;155(6):3013-3020.

10. Madsen HO, Garred P, Kurtzhals JA, et al. A new frequent allele is the missing link in the structural polymorphism of the human mannanbinding protein. Immunogenetics. 1994;40(1):37-44.

11. Garred P, Madsen HO, Balslev U, et al. Susceptibility to HIV infection and progression of AIDS in relation to variant alleles of mannosebinding lectin. Lancet. 1997;349(9047):236-240.

12. Denholm JT, McBryde ES, Eisen DP. Mannose-binding lectin and susceptibility to tuberculosis: a meta-analysis. Clin Exp Immunol. 2010;162(1):84-90.

13. Higgins JP, Thompson SG. Quantifying heterogeneity in a meta-analysis. Stat Med. 2002;21(11):1539-1558.

14. Boissel JP, Sacks HS, Leizorovicz A, Blanchard J, Panak E, Peyrieux JC. Meta-analysis of clinical trials: summary of an international conference. Eur J Clin Pharmacol. 1988;34(6):535-538.

15. Lau J, Ioannidis JP, Schmid CH. Quantitative synthesis in systematic reviews. Ann Intern Med. 1997;127(9):820-826.

16. Begg CB, Mazumdar M. Operating characteristics of a rank correlation test for publication bias. Biometrics. 1994;50(4):1088-1101.

17. Egger M, Davey Smith G, Schneider M, Minder C. Bias in metaanalysis detected by a simple, graphical test. BMJ. 1997;315(7109): 629-634.

18. Zhao H, Zhu G, Chen D, et al. Association between polymorphism of MBL gene rs1800450 with susceptibility to tuberculosis in Ningxia. J Ningxia Med Univ. 2014;36(8):889-893.

19. Li Y. Associations between NRAMP1, MBL SNPs and tuberculosis in the Ningxia Haiyuan Hui Pepole: genetics. (Master dissertation) Ningxia Medical University, Ningxia, China. 2009;1-40.

20. LiY, Wu F, Zhang L, et al. Association between polymorphism of MBL gene with susceptibility to tuberculosis in Han Population in Xinjiang. Chin J Zoonoses. 2011;27(9):769-773.

21. Fang G, Yin C. Research on relationship of polymorphism of mannosebinding lectin gene with susceptibility to tuberculosis in Zhuang population. Int J Respir. 2011;31(6):428-430.

22. Zhou J, Zhang W. Correlation between MBL-A/B gene with the susceptibility of tuberculosis in Xinjiang Uighur population. JChin Antituberc Assoc. 2012;7:445-451.

23. Liu Y, Guo Y, Jiang G, et al. Study on relation between regulation of MBL level and pulmonary tuberculosis susceptibility. Int J Lab Med. 2016;37(13):1767-1769.

24. Wu L, Deng H, Zheng Y, et al. An association study of NRAMP1, VDR, MBL and their interaction with the susceptibility to tuberculosis in a Chinese population. Int J Infect Dis. 2015;38:129-135.

25. Thye T, Niemann S, Walter K, et al. Variant G57E of mannose binding lectin associated with protection against tuberculosis caused by Mycobacterium africanum but not by M. tuberculosis. PLoS One. 2011;6(6):e20908.

26. Soborg C, Madsen HO, Andersen AB, Lillebaek T, Kok-Jensen A, Garred P. Mannose-binding lectin polymorphisms in clinical tuberculosis. J Infect Dis. 2003;188(5):777-782.
27. Singla N, Gupta D, Joshi A, Batra N, Singh J, Birbian N. Association of mannose-binding lectin gene polymorphism with tuberculosis susceptibility and sputum conversion time. Int J Immunogenet. 2012;39(1): $10-14$.

28. Selvaraj P, Narayanan PR, Reetha AM. Association of functional mutant homozygotes of the mannose binding protein gene with susceptibility to pulmonary tuberculosis in India. Tuber Lung Dis. 1999;79(4):221-227.

29. Selvaraj P, Jawahar MS, Rajeswari DN, Alagarasu K, Vidyarani M, Narayanan PR. Role of mannose binding lectin gene variants on its protein levels and macrophage phagocytosis with live Mycobacterium tuberculosis in pulmonary tuberculosis. FEMS Immunol Med Microbiol. 2006;46(3):433-437.

30. Ozbas-Gerceker F, Tezcan I, Berkel AI, et al. The effect of mannosebinding protein gene polymorphisms in recurrent respiratory system infections in children and lung tuberculosis. Turk $J$ Pediatr. 2003;45(2):95-98.

31. Ocejo-Vinyals JG, Lavin-Alconero L, Sanchez-Velasco P, et al. Mannose-binding lectin promoter polymorphisms and gene variants in pulmonary tuberculosis patients from cantabria (northern Spain). Pulm Med. 2012;2012:469128.

32. Liu W, Zhang F, Xin Z-T, et al. Sequence variations in the MBL gene and their relationship to pulmonary tuberculosis in the Chinese Han population. Int J Tubelc Lung Dis. 2007;2(1):49-54.

33. Liu C, He T, Rong Y, et al. Association of mannose-binding lectin polymorphisms with tuberculosis susceptibility among Chinese. Sci Rep. 2016;6:36488.

34. Garcia-Laorden MI, Pena MJ, Caminero JA, et al. Influence of mannosebinding lectin on HIV infection and tuberculosis in a Western-European population. Mol Immunol. 2006;43(14):2143-2150.

35. Garcia-Gasalla M, Mila LJ, Losada-Lopez I, et al. Mannose-binding lectin exon 1 and promoter polymorphisms in tuberculosis disease in a Mediterranean area. Int J Immunogenet. 2014;41(4):306-311.

36. Fitness J, Floyd S, Warndorff DK, et al. Large-scale candidate gene study of tuberculosis susceptibility in the Karonga district of northern Malawi. Am J Trop Med Hyg. 2004;71(3):341-349.

37. Da CH, Da SR, Segat L, et al. MBL2 gene polymorphisms and susceptibility to tuberculosis in a northeastern Brazilian population. Infect Genet Evol. 2013;19:323-329.

38. Cosar H, Ozkinay F, Onay H, et al. Low levels of mannose-binding lectin confers protection against tuberculosis in Turkish children. Eur J Clin Microbiol Infect Dis. 2008;27(12):1165-1169.

39. Capparelli R, Iannaccone M, Palumbo D, et al. Role played by human mannose-binding lectin polymorphisms in pulmonary tuberculosis. J Infect Dis. 2009;199(5):666-672.

40. Bellamy R, Ruwende C, McAdam KP, et al. Mannose binding protein deficiency is not associated with malaria, hepatitis B carriage nor tuberculosis in Africans. QJM. 1998;91(1):13-18.

41. Araujo MS, Graca ES, Azevedo VN, et al. No evidence of association between MBL2A/O polymorphisms and Mycobacterium tuberculosis infection in populations from the Brazilian Amazon region. Hum Immunol. 2013;74(1):82-84.

42. Amiri A, Sabooteh T, Shahsavar F, Anbari K, Pouremadi F. Mannosebinding lectin (MBL) gene polymorphisms in susceptibility to pulmonary tuberculosis among the Lur population of Lorestan Province of Iran. Genom Data. 2017;12:146-150.

43. Alagarasu K, Selvaraj P, Swaminathan S, Raghavan S, Narendran G. Mannose binding lectin gene variants and susceptibility to tuberculosis in HIV-1 infected patients of South India. Tuberculosis (Edinb). 2007;87(6):535-543.

44. McShane H. Susceptibility to tuberculosis - the importance of the pathogen as well as the host. Clin Exp Immunol. 2003;133(1):20-21.

45. Bellamy R. Susceptibility to mycobacterial infections: the importance of host genetics. Genes Immun. 2003;4(1):4-11.

46. Areeshi MY, Mandal RK, Akhter N, et al. A Meta-analysis of MBL2 polymorphisms and tuberculosis risk. Sci Rep. 2016;6:35728. 
47. Feng F, Wang D, Guo M, et al. A case control study on mannose-binding protein genetic polymorphism and susceptibility to pulmonary tuberculosis. Mod Prev Med. 2007;34(3):438-440.

48. Hijikata M, Matsushita I, Hang NT, et al. Age-dependent association of mannose-binding lectin polymorphisms with the development of pulmonary tuberculosis in Viet Nam. Hum Immunol. 2014;75(8): $840-846$

49. Soborg C, Andersen AB, Range N, et al. Influence of candidate susceptibility genes on tuberculosis in a high endemic region. Mol Immunol. 2007;44(9):2213-2220.

50. Feng F, Guo M, Liu Q, et al. Study on mannose - binding protein gene polymorphisms and susceptibility to pulmonary tuberculosis. Chin J Epidemiol. 2006;27(12):1082-1085.

51. Ceylan E, Karkucak M, Coban H, Karadag M, Yakut T. Evaluation of TNF-alpha gene (G308A) and MBL2 gene codon 54 polymorphisms in Turkish patients with tuberculosis. J Infect Public Health. 2017;10(6):774-777.

52. Feng X, Yang C, Guan W, et al. Correlations between the mannosebinding lectin (MBL) gene polymorphisms and the susceptibility to tuberculosis in Tibetan population in Qinghai province. Chin J Microbiol Immunol. 2016;36(11):838-842.
53. de Wit E, van der Merwe L, van Helden PD, Hoal EG. Gene-gene interaction between tuberculosis candidate genes in a South African population. Mamm Genome. 2011;22(1-2):100-110.

54. Wang F. Study on Mechanism and Relation Between MBL Polymorphisms and Pulmonary Tuberculosis Susceptibility in Chinese Han Population: Microbiology. (PhD dissertation) Fudan University, Shanghai, China. 2009;40-70.

55. Feng F, Hao Q, Chen Y, et al. Relationship of gene-gene interaction of VDR and MBP loci with susceptibility to pulmonary tuberculosis of Han population in Tangshan Hebei. Chongqing Med. 2010;39(12):1527-1529;1532.

56. Garred P, Thiel S, Madsen HO, Ryder LP, Jensenius JC, Svejgaard A Gene frequency and partial protein characterization of an allelic variant of mannan binding protein associated with low serum concentrations. Clin Exp Immunol. 1992;90(3):517-521.

57. Lipscombe RJ, Sumiya M, Hill AV, et al. High frequencies in African and non-African populations of independent mutations in the mannose binding protein gene. Hum Mol Genet. 1992;1(9):709-715.

58. Garred P, Madsen HO, Kurtzhals JA, et al. Diallelic polymorphism may explain variations of the blood concentration of mannan-binding protein in Eskimos, but not in black Africans. Eur $J$ Immunogenet 1992;19(6):403-412. 


\section{Supplementary material}

\section{Literature retrieval formula}

The exact combination of search terms:

((()((()((polymorphism, single nucleotide) OR SNP) OR polymorphism) OR variant) OR variation) OR allele) $O R$ single nucleotide polymorphism)) AND (('mannose-binding lectin 2') OR MBL2)) AND tuberculosis)) OR (((rs1800450) OR rs1800451) OR rs5030737).

\section{Publish your work in this journal}

Infection and Drug Resistance is an international, peer-reviewed openaccess journal that focuses on the optimal treatment of infection (bacterial, fungal and viral) and the development and institution of preventive strategies to minimize the development and spread of resistance. The journal is specifically concerned with the epidemiology of antibiotic resistance and the mechanisms of resistance development and diffusion in both hospitals and the community. The manuscript management system is completely online and includes a very quick and fair peerreview system, which is all easy to use. Visit http://www.dovepress.com/ testimonials.php to read real quotes from published authors. 